\title{
PERGULATAN PENDIDIKAN AGAMA ISLAM DI KAWASAN MINORITAS MUSLIM
}

\author{
Abdul Wahib \\ IAIN Walisongo Semarang \\ e-mail: abdulwahib@yahoo.com
}

\begin{abstract}
This study was conducted with a qualitative approach. Data obtained by in-depth interviews, observation and documentation. Data were analyzed by phenomenological qualitative analysis model. This study concluded: (1) about the life of the Muslim minority in the school before and after the bombing; With imitate the concept of immersion, the good relations established between the Hindu-Muslim, but the bombs are up to two times it has damaged the relationship patterns that have progress, (2) the internal problems of PAI Teachers: The teachers of Islamic religious education in Bali faced a different problem that encompasses many domains of life. In school/classroom, in social life and so on, (3) materials additional Islamic Education, also called local curriculum include: Instilling a sense of respect for people who embrace different beliefs.

Kajian ini merupakan kajian dengan pendekatan kualitatif. Data penelitian diperoleh dengan wawancara mendalam, observasi, dan dokumentasi. Data dianalisis dengan analisis fenomenologi. Kesimpulan dari kajian ini adalah: (1) terkait dengan kehidupan minoritas muslim disekolah sebelum dan sesudah peristiwa peledakan bom:hubungan yang semula baik kemudian menjadi rusak; (2) problem internal guru-guru PAI: Guru-guru PAI di Bali menghadapi masalah yang rentangnya sangat beragam terkait dengan wilayah kehidupan: sekolah, ruang kelas, dan kehidupan sosial; (3) bahan dalam kurikulum lokal: perlu dimasukkannya materi tentang penghormatan terhadap penganut keyakinan yang berbeda.
\end{abstract}

Keywords: Pendidikan Agama Islam, minoritas, survive 


\section{A. Pendahuluan}

Bali dengan masyarakat dan budaya yang unik dipastikan bukanlah satu wilayah migrasi yang baru tumbuh. Keseharian masyarakat Bali dengan budaya yang senantiasa menampilkan warna budaya lokal menunjukkan bahwa perjalanan Bali telah melewati alur sejarah yang panjang. Berbagai temuan arkeologi di berbagai wilayah Bali membuktikan perjalanan panjang Pulau Bali berbarengan dengan wilayah dan pulau lain.

Dahulu kala, budaya lokal Bali Kuno berbenturan dengan budaya Hindu Jawa dari Majapahit yang migrasi ke Bali karena terdesak oleh perkembangan Islam dari Kesultanan Demak. Penolakan penduduk Bali menimbulkan berbagai perlawanan di berbagai daerah di Bali. Secara perlahan dan pasti, dengan upaya penyesuaian dan percampuran kedua belah pihak, Bali berhasil menemukan pola budaya yang sesuai dengan pola pikir masyarakat dan keadaan alam Bali.

Model penyesuaian ini kiranya yang kemudian membentuk masyarakat dan budaya Bali yang diwarisi kini menjadi unik dan khas, menyerap unsur Hindu dan Jawa Majapahit namun kental dengan warna lokal.

Pola perkembangan budaya Bali di masa-masa berikutnya, pada jaman penjajahan dan jaman kemerdekaan, secara alamiah mengikuti alur yang sama yaitu menerima pengaruh luar yang dilebur ke dalam warna budaya lokal. Sebagai contoh, dari sisi arsitektur rumah, kaum pendatang boleh mendesain rumah sesuai dengan kultur arsitektural yang dibawa dari tanah asal tetapi warna khas Bali harus dimasukkan. Ketentuan tidak boleh membangun rumah yang lebih tinggi dari pohon kelapa juga harus diperhatikan.

Di Bali dikenal satu bait sastra yang intinya digunakan sebagai slogan lambang negara Indonesia, yaitu: Bhineka Tunggal Ika Tan Hana Dharma Manggrua, yang bermakna 'Kendati berbeda namun tetap satu jua, tiada duanya (Tuhan-Kebenaran) itu'. Bisa dipahami jika masyarakat Bali dapat hidup berdampingan dengan pemeluk agama lain seperti Islam, Kristen, Budha, dan lainnya. Pada masyarakat Bali dikenal juga budaya "menyama braya", yakni persaudaraan yang betul-betul diterapkan dalam kehidupan umat beragama di Bali. ${ }^{1}$ Dengan konsep menyama braya yang secara harfiah berarti saudara

1 Mudzakkir, Kasi Bina Ibadah Sosial, Produk Halal dan Kemitraan Bimas Islam dan Penyelenggara Haji Kanwil Departemen Agama Provinsi Bali, dalam http://www. kabarindonesia.com 
sekampung ini, maka bagi orang Bali orang dari daerah lain atau bahkan dari agama lain tetap diterima sebagai orang sekampung, orang dekat bukan orang asing.

Kehidupan umat beragama yang "mesra dan harmonis" yang selama ini dapat diwujudkan di Pulau Dewata tetap terpelihara guna mendukung terciptanya kondisi yang aman, nyaman dan tenteram, sekaligus memberikan kesejukan di hati siapa saja. Dampak dari ini semua tentu kembali pada siapa saja yang tinggal di Bali.

Masyarakat Bali menganggap masyarakat Muslim yang datang ke daerahnya sebagai saudara. Nyama Selam, sebutan penghormatan warga Bali kepada kaum Muslim di Pulau Dewata itu. Nyama punya makna saudara, sementara selam artinya Islam².

Meskipun secara umum tidak ada letupan krusial yang muncul di permukaan terkait relasi Hindu-Muslim, bukan berarti relasi mayoritasminoritas ini tidak ada masalah sama sekali. Masalah besar yang kelihatannya sederhana, misalnya, dalam hal sulitnya orang Islam mendirikan masjid. Jika masjid akhirnya juga berdiri, maka tidak diperbolehkan menggunakan pengeras suara. Selain itu, beberapa saat setelah Megawati kalah dari Gus Dur dalam voting pemilihan presiden ada beberapa masjid yang dilempari batu.

Dalam hal pelaksanaan Pendidikan Agama Islam di sekolah, beberapa masalah tak bisa dielakkan. Mulai dari mushalla yang tidak tersedia, pada jam siswa Muslim mesti melaksanakan shalat Jum'at tapi pelajaran tetap terus berlangsung sampai, bahkan, ruang kelas khusus bagi siswa untuk mata pelajaran Agama Islam juga tidak tersedia.

Dua kali pengeboman di Bali yang dilakukan kelompok Amrozi dan kawan-kawannya jelas menimbulkan kontra-reaksi di kalangan masyarakat mayoritas Hindu Bali. Hasilnya, kaum Muslimin yang sebenarnya tidak ada urusan dengan Amrozi cs menerima dampaknya dalam bentuk meningkatnya kesulitan-kesulitan kehidupan keagamaan yang tidak pernah mereka alami sebelumnya. ${ }^{3}$

\footnotetext{
2 Ayu Sulistyowati, "Nyama Selam" dan Harmonisasi di Pulau Dewata," dalam artikel online http://www.kompas.com/kompas-cetak/0510/28/lebaran/2158687.htm

3 Azyumardi Azra, "Psikologi Minoritas - Mayoritas," Majalah Gatra, edisi khusus Kamis, 25 September 2008.
} 
Dua kali ledakan bom itu, jelas menorehkan luka bahkan trauma yang berat bagi masyarakat Hindu Bali. Oleh karena itu, beberapa saat setelah ledakan bom kedua, isu pengusiran orang-orang Islam semakin menguat. Isu ini menyebar dari handphone ke handphone melalui SMS. Isu tersebut menyebar di kalangan orang-orang Islam sebagai warning agar orang Islam betul-betul siap mental jika harus terpaksa angkat kaki dari Bali. Tas-tas wanita berjilbab diperiksa satu persatu jika ingin masuk pasar swalayan atau mall dan berbagai perlakuan lain yang kurang menyenangkan.

Di lembaga pendidikan formal guru-guru Agama Islam di sekolah mendapatkan tantangan dan kesulitan yang tidak kalah peliknya. Guru Agama Islam dicibir, diolok-olok dan "diminta pertanggungjawaban" atas kesalahan yang sama sekali tidak mereka lakukan bahkan mereka pahami. Guru Agama Islam harus menjawab pertanyaan-pertanyaan yang datangnya dari pihak Muslim dan Hindu sekaligus.

Sementara masalah klasik berupa mushalla yang tidak tersedia, tidak ada kesempatan melaksanakan shalat Jum'at bagi siswa Muslim dan tidak ada ruangan khusus untuk melaksanakan proses belajar mengajar Pendidikan Agama Islam tetap jalan terus.

Dinamika para guru Pendidian Agama Islam di sekolah, mulai dari problem-problem yang selama ini mereka hadapi, juga perjuangan mereka untuk tetap survive di tengah-tengah kesulitan yang menantang adalah sumber informasi dan pengetahuan yang menarik. Dinamika mereka dapat menjadi insprirasi bagi "guru-guru" Agama Islam yang berada pada kawasan bumi lain.

Untuk itu semua, sebagai langkah awal, peneliti bermaksud untuk melakukan penelitian dengan judul; Pergulatan Pendidikan Agama Islam di Kawasan Minoritas Muslim (Studi Kasus PAI di Bali Pra dan Pasca Bom Bali)

\section{B. Agama Minoritas}

\section{Relasi Muslim - Non Muslim}

Kajian yang dilakukan oleh para akademisi yang secara spesifik mengupas tentang relasi Islam-Hindu di Indonesia masih sangat terbatas. Oleh karena itu, dalam tinjauan pustaka ini peneliti tampilkan relasi antar agama yang ada, yakni relasi Islam-Nasrani. Beberapa kajian yang pernah dilakukan 
oleh para sarjana yang mengambil object penelitian tentang relasi agama di antaranya karya Aqib Suminto, Politik Islam Hindia Belanda: Het Kantoor voor Inlandsche zaken (Jakarta: LP3ES, 1985). Dalam penelitiannya, Suminto mendiskripsikan peranan Kantor (Agama) pada masa Pemerintahan Kolonial Belanda, status, tugas-tugas dan kebijakan yang berkaitan dengan keagamaan di Indonesia. Dia juga memaparkan secara umum kebijakan politik kolonial Belanda terhadap Islam.

Dalam penelitian ini pula juga ditemukan perlakuan diskriminasif pemerintah kolonial Belanda, khusunya berkaitan dengan kebijakan pemerintah dalam memberikan bantuan finansial kepada masyarakat Islam dengan bantuan yang diterima oleh masyarakat Kristen (Nasrani). Kesimpulan yang dapat ditarik dari penelitian Suminto adalah terdapat mata rantai yang erat antara agama (kekristenan) dengan penguasa (Kolonial Belanda). ${ }^{4}$

Karya lain yang juga mengambil subjek kajian tentang relasi antar agama di Indonesia adalah disertasi Alwi Shihab: The Muhammadiyah Movement and its Controversy with Christian Mission. Gagasan utama Shihab adalah untuk menerangkan faktor penting yang mendasari kelahiran $\mathrm{Mu}-$ hammadiyah sebagai salah satu gerakan pembaharuan yang paling berpengaruh di Indonesia. Disebutkan bahwa salah satu dari faktor utama kelahiran Muhammadiyah, menurut Shihab, adalah kuatnya penetrasi misi kekristenan ke seluruh pelosok wilayah Nusantara. ${ }^{5}$ Dengan kata lain, penetrasi suatu ide atau agama baru akan menimbulkan reaksi bahkan resistensi dari kamunitas lama yang tidak setuju.

Untuk ruang lingkup yang lebih kecil, D.P. Budi Susetyo dan St. Hardiyarso juga melakukan penelitian mengenai relasi Muslim-Nasrani dalam kehidupan kampus dengan judul Stereotip dalam Relasi Antar Agama: Studi pada Mahasiswa Islam dan Kristiani di Universitas Katolik Soegijapranata Semarang. Studi ini menyimpulkan bahwa hal yang mendasari munculnya stereotype agama adalah faktor identitas sosial khas yang ditampilkan masing-masing pemeluk agama dalam perilakunya sehari-hari serta adanya pluralisme dalam penghayatan beragama. Artinya, prasangka yang berkembang dalam relasi

\footnotetext{
${ }^{4}$ Aqib Suminto, Politik Islam Hindia Belanda: Het Kantoor voor Inlandsche Zaken, (Jakarta: LP3ES, 1985).

${ }^{5}$ Alwi Shihab, "The Muhammadiyah Movement and It's Controversy with Christian Mission," Ph.D. dissertation, Temple University, 1995.
} 
antar agama lebih disebabkan karena faktor kesempatan interaksi dan kesiapan mental untuk terbuka terhadap pluralisme agama. Penelitian ini juga menemukan bahwa intensitas prasangka subjek mahasiswa Kristiani (mayoritas yang lebih dulu eksis) terhadap orang beragama Islam (minoritas "pendatang") lebih kuat dibandingkan dengan subjek mahasiswa Muslim (minoritas) terhadap orang beragama Kristiani (mayoritas). ${ }^{6}$

Hasil penelitian lain yang bisa ditemukan adalah penelitian yang dilakukan oleh Abdul Kholiq dkk, yang berjudul "Peran Sosial Gereja dalam Konteks Relasi Muslim-Nasrani (Studi Kasus terhadap Peran Sosial Gereja Katedral Semarang)". Penelitian ini bertujuan untuk mengetahui peran sosial yang dilakukan oleh Gereja Katedral di Semarang, respon masyarakat Muslim dan Nasrani terhadap peran sosial Gereja Katedral Semarang dan untuk mengetahui peran sosial gereja dalam konteks relasi Muslim-Nasrani di Kota Semarang.

Di antara hasil penelitian ini ialah bahwa peran sosial geraja, sebagai agama minoritas tidak dimasalahkan oleh komunitas Muslim mayoritas yang menerima pean sosial itu. Peran sosial itu justru dipermasalahkan oleh kalangan yang berada di luar komunitas penerima dengan argumen bahwa peran sosial itu hanya sebagai entry point untuk peran-peran lain di luar konteks peran sosial. Ada kecurigaan bahwa penetrasi keagamaan yang cepat atau lambat akan terjadi di balik peran sosial tersebut. Walhasil, relasi antar agama tak bisa steril dari adanya curiga atau setidaknya waspada.

\section{Fiqh Minoritas}

Rumusan-rumusan tentang hubungan Muslim dan non-Muslim terutama dalam masyarakat/negara minoritas Muslim memang belum dirumuskan oleh ulama-ulama pada masa lalu, karena para ulama saat itu hidup di wilayah mayoritas Muslim.

Baru akhir-akhir ini, sejumlah ulama memperkenalkan fiqh al-aqalliyyat (fiqh minoritas) seperti yang disampaikan oleh Dr. Taha Jabir al-Alwani (Amerika Serikat) dengan bukunya berjudul Towards A Fiqh For Minorities:

6 D.P. Budi Susetyo dan St. Hardiyarso, " Stereotip dalam Relasi antar Agama-Studi pada Mahasiswa Islam dan Kristiani di Universitas Katolik Soegijpranata" dalam Proseding Workshop dan Seminar Nasional Hasil-hasil Penelitian, Balitbang Provinsi Jawa Tengah, 16 Desember 2003., h. A.I.3. 3 dan 8. 
Some Basic Reflections dan Dr. Yusuf al-Qardhawi dengan bukunya berjudul Fi Fiqh al-Aqalliyyat al-Muslimah.

Sedangkan di Eropa, hal ini dikemukakan oleh Tariq Ramadhan, meski ideidenya belum terumuskan secara sistematis. "Di Indonesia sendiri saya rasa baru ICIS yang mengungkapkan," tandasnya. Fiqh minoritas ini muncul dengan tujuan meringankan beban dan mengurangi kesulitan-kesulitan umat Islam yang hidup di wilayah mayoritas non-Muslim, terutama dalam bidang mu'amalah.

Hal ini diperlukan agar umat Islam mendapatkan kemaslahatan dengan legitimasi keagamaan atas tindakan yang tidak sesuai sepenuhnya dengan fiqh umum (standar). Dalam kaitan ini, para ulama dan cendikiawan Muslim diharapkan melakukan kajian mendalam tentang fiqh minoritas.

Umat Islam yang tinggal di wilayah minoritas non-Muslim hendaknya melakukan interaksi, menjaga pergaulan yang baik dan menghindari konflik dengan warga non-Muslim. Setiap Muslim diharapkan bisa membedakan antara aqidah dan pergaulan serta bisa memposisikan dan menyesuaikan diri tanpa mengorbankan aqidah.

Karena kondisi umat Islam minoritas tidak selamanya sama dengan kondisi umat Islam mayoritas, untuk itu diperlukan penyesuaian. Umat Islam, harus ikut bergaul, ada interaksi dengan kelompok lain, tapi tetap menjaga aqidah. Misalnya di wilayah Bali ada sebuah seremonial yang disertai ritual. Jika hanya seremonial saja, datang tidak apa, asal jangan terlibat dalam ritual tersebut. Tak hanya itu, Fiqh minoritas juga mengatur masalah umat Islam minoritas yang bermukim di wilayah mayoritas non-Muslim seyogianya mempertahankan identitas budaya di wilayah dimana para Muslim minoritas tinggal/hidup, dengan tetap menjaga ajaran dan nilai-nilai aqidah Islam.

Umat Islam minoritas dapat menyampaikan aspirasi sesuai dengan ajaran dan nilai-nilai aqidah Islam, namun seyogianya dapat diekspresikan dengan cara yang hikmah dan bijaksana serta dilakukan dengan cara damai. Di sisi lain pemerintah diharapkan juga memperlakukan kelompok minoritas Muslim secara adil dan proporsional. ${ }^{7}$

Dalam masyarakat Indonesia yang sedang mengalami krisis dan berjuang untuk memperbaharui diri, cita-cita untuk membangun kerukunan

7 Masykuri, http://islamic-center.or.id/berita-mainmenu-26/duniaislam-mainmenu-27/19duniaislam/496-icis-perkenalkan-fiqh-minoritas?tmpl=component\&print=1\&page= 
hidup beragama bukan saja menjadi tanggung jawab pemerintah, namun oleh seluruh komponen warga beragama itu sendiri.

Perenungan untuk membangun kembali persaudaraan sejati di tanah air ini, dirasa perlu mengingat beberapa hal, pertama, kita hidup dalam masyarakat yang plural, termasuk pluralitas dalam beragama dan berkeyakinan, sebagai fakta yang tidak dapat ditolak atau dihindari; atau dengan kata lain pluralitas agama merupakan keniscayaan yang harus kita terima sebagai wujud kehendak dan anugerah Tuhan. ${ }^{8}$

Kedua, wujud empirik, memberikan pemahaman bahwa banyak upaya untuk mempolitisir agama dengan menjadikan agama sebagai alat atau kendaraan politik (demi harta atau kekuasaan) sehingga mudah untuk membakar emosi massa dan memporak-porandakan bangunan persaudaraan sejati yang telah baik dan mengakar di masyarakat basis (grass root); upayaupaya itu kebanyakan dilakukan oleh para politikus bombongan yang ingin mencari dukungan dan mengejar popularitas murahan. ${ }^{9}$

Ketiga, jauh ke depan kita memerlukan keterbukaan sikap untuk menerima dan menghayati hidup dalam pluralitas itu; dengan kata lain, kita harus benar-benar terbuka dan mau menerima keberagamaan, bukan karena terpaksa tetapi berani memaknai secara positif bahwa perbedaan adalah sumber kekayaan, perbedaan adalah rahmat dan bukan bencana.

Dengan belajar secara inklusif (terbuka), kita dituntut menciptakan jalan untuk mengembalikan agama pada salah satu fungsi dasarnya yaitu pemandu moral bangsa, yang sudah betul-betul compang-camping. Apa yang bisa kita gunakan untuk menjembatani kesenjangan hubungan antar umat beragama? Mengutip pendapat Nurcholis Madjid.10

8 Nasikun, dengan mengutip pemikiran Furnival (1939) dan Smith (1965), mendefinisikan masyarakat majemuk sebagai masyarakat yang terdiri atas dua atau lebih karakteristik sosial, atau kelompok yang secara kultural dan ekonomik terpisah satu dengan yang lain dan memiliki struktur kelembagaan yang berbeda. Lihat Nasikun, Nasionalisme: Refleksi Kritis Kaum Ilmuwan, (Yogyakarta: Pustaka Pelajar, 1996), h. 5.

9 Dadang Kahmad, mengemukakan teori tersebut dalam bukunya yang berjudul Against Religion: Why We Should Try to Live Without It. Teori tersebut dilhami oleh pernyataan sikap paus yang mengecam pihak-pihak yang tidak toleran terhadap keberagamaan orang lain. Lihat Dadang Kahmad, Sosiologi Agama, (Bandung: Rosdakarya, 2000), h. 165. 2000.

10 Disampaikan pada peresmian Badan Interaksi Sosial Masyarakat/BISMA di Jakarta, 6 Juli 
Kita mempunyai titik temu yang dapat mempersatukan kita antar umat beragama. Paling tidak dalam bahasa yang sangat halus, kita dipertemukan oleh nilai-nilai kemanusiaan universal. Nilai-nilai yang harus kita tanamkan lagi adalah kesucian kemanusiaan universal. Kedalaman hidup keagamaan adalah jangkar yang harus kita diperhatikan. Bukan lagi saatnya untuk bertengkar hanya karena lambang-lambang atau simbol-simbol keagamaan yang berbeda. Tugas kita adalah membuat agama kembali berfungsi. Ada kesatuan antara kata dan perbuatan, antara ajaran dan tindakan, antara khotbah dan praktek dalam hidup sehari-hari.

Kajian psikologi konflik antar agama sangat disarankan dalam rangka menemukan solusi yang komprehensif atas problem ketegangan dan konflik antar pemeluk agama. Hal ini dikarenakan ketegangan hubungan antar umat beragama seringkali lebih ditentukan oleh faktor persepsi yang subjektif.

Institusi-institusi agama baik masjid, gereja, wihara atau pura merupakan lembaga-lembaga yang sangat strategis untuk memainkan peran pendidikan sosial. Lintas sejarah agama-agama membuktikan bahwa masjid, gereja atau lembaga-lembaga agama lainnya tidak hanya sekedar berfungsi sebagai tempat-tempat ibadah, namun dalam realitasnya efektif dalam memerankan fungsi pendidikan dan sosial. Dalam konteks kondisi krisis seperti yang terjadi dewasa ini, banyak masyarakat yang membutuhkan uluran tangan dari pihak manapun, untuk sekedar menyambung hidup.

Sudah sepatutnya lembaga-lembaga agama melakukan upaya untuk menumbuhkan sikap saling memahami dan mendukung kelompok atau agama lain agar tetap eksis bukan sebaliknya (sikap proeksisten).

\section{Pergulatan Pendidikan Agama Islam di Kawasan Minoritas}

Pendidikan adalah warisan paling berharga yang bisa diberikan oleh genarasi terdahulu kepada generasi berikutnya. Demikian juga pendidikan Agama, pendidikan agama adalah warisan bagi generasi penerus agar bisa hidup lebih terarah dan bermakna. Pendidikan agama diyakini menjadi salah satu cara agar moralitas para siswa tetap terjaga sampai pada hari tuanya kelak.

Pendidikan Agama Islam di sekolah menjadi concern dari berbagai pihak; sekolah, guru Agama Islam, orang tua, dan juga anak itu sendiri. Hal ini terjadi karena bagi lembaga pendidikan memberikan pendidikan agama 
sesuai agama yang dipeluk oleh para siswa adalah hak siswa dan kewajiban sekolah sesuai Undang-Undang Sistem Pendidikan Nasional. Para guru Pendidikan Agama Islam sangat concern karena ini adalah tanggung jawab moral mereka, sementara orang tua juga merasa bertanggung jawab untuk memberikan kepada anak-anak mereka pendidikan agama dengan harapan kelak putra-putrinya menjadi anak yang saleh dan salehah.

Meskipun Pendidikan Agama Islam menjadi concern dari berbagai pihak, namun untuk kasus Bali, Pendidikan Agama Islam tetaplah sesuatu yang eksotik. Letak eksotiknya berada pada adanya kenyataan bahwa Islam adalah minoritas dan lebih istimewa lagi karena adanya kasus ledakan Bom yang terjadi dua kali di mana para pelakuknya adalah orang Islam.

Penelitian ini mengambil lokasi di tiga sekolah, yakni SMAN Kamboja Denpasar, SMPN Jimbaran dan SMPN Tanjung Benoa. Pemilihan lokasi dilakukan dengan pertimbangan SMAN Kamboja dipilih karena guru agamanya asli penduduk Bali dan keturunan Islam, di samping itu Denpasar adalah kota metropolit, di sinilah komunitas Islam paling banyak di Provinsi Bali. Sementara SMPN Jimbaran dipilih karena sekolah ini hanya beberapa ratus meter dengan lokasi Bom Bali 2 sehingga dampak ledakan secara psikologis sangat dirasakan, sedangakan SMPN 3 Tanjung Benoa dipilih karena sekolah ini di kawasan yang setingkat di bawah Denpasar dari segi pluralitas agama penduduknya sementara guru maupun siswanya mayoritas beragama Hindu.

Metode yang digunakan dalam pengumpulan data meliputi metode observasi, wawancara mendalam dan dokumentasi. Observasi digunakan untuk melihat proses belajar mengajar yang berlangsung baik yang diselenggarakan di kelas maupun di luar kelas, juga untuk melihat suasana kerja para guru informan. Wawancara digunakan untuk mendapatkan data tentang problem-problem pelaksanaan Pendidikan Agama Islam di sekolah juga untuk mendapatkan data tentang "kurikukum muatan lokal" yang diajarkan di sekolah dan berbagai data yang lain. Sementara metode dokumen digunakan untuk mendapatkan data tentang sejarah sekolah, visi missi juga jumlah siswa Muslim yang ada.

\section{Kesimpulan}

Setelah mengumpulkan data, peneliti menyimpulkan hasil-hasil penelitian ini dalam tiga poin utama sebagai berikut: 


\section{Kehidupan Minoritas Muslim di Sekolah Pra dan Pasca Tragedi Bom Bali}

\section{a. Harmoni Relasi}

Hubungan baik atau buruk lebih banyak ditentukan oleh sikap atau perilaku seseorang pada orang lain bukan semata karena faktor agama. Dengan konsep Nyama selam, selama berpuluh atau bahkan mungkin beratus-ratus tahun, relasi yang baik terjalin antara Hindu-Islam karena memang tak ada yang perlu dimasalahkan. Akan tetapi terjadinya bom yang sampai dua kali itu menghentak, mengusik dan merusak pola relasi yang selama berpuluhpuluh tahun sudah berlangsung secara simbiosis mutualis. Orang Islam dibenci dan dicurigai, diolok-olok dan dipersalahkan atas apa yang sama sekali tidak mereka pahami apalagi mereka lakukan. Tragedi itu menyisakan berbagai kegetiran kepada kedua belah pihak. Kedua belah pihak tidak ada yang salah dalam hal ini, hanya saja butuh waktu untuk akhirnya bisa memahami bahwa relasi mereka mesti dirajut ulang. Demi masa depan bersama yang lebih baik.

\section{b. Keleluasaan Beribadah}

Memang benar bahwa sarana ibadah bagi umat Islam berupa masjid atau mushalla belum dimiliki oleh semua lembaga pendidikan, akan tetapi kebebasan beribadah tetap dijamin oleh sekolah. Baik sebelum maupun setelah terjadinya tragedi itu dalam masalah kebebasan beribadah tetaplah sama. Dan pemahaman lebih jauh tentang seluk beluk Islam cenderung lebih meningkatkan pemahaman terhadap Islam dan ini lebih berarti positif bagi kehidupan warga sekolah yang Muslim.

\section{c. Pertanyaan tentang Anarkisme dan Jihad dalam Islam}

Islam, selama ini dimengerti oleh sebagian besar orang Bali sebagai agama yang ramah, banyak senyum, mau menghormati keyakinan dan ritual para pemeluk agama Hindu, oleh karena itu mereka pun menghormati orang Islam dan menerima keberadaan mereka. Pasca tragedi, mereka menjadi ngeri bila orang-orang Islam yang ada di Bali kemudian menjadi seperti apa yang ditayangkan di media massa itu. Betapa kacaunya nanti Bali. Oleh karena itu mereka mempertanyakan dengan sungguh-sungguh apa itu Front 
Pembela Islam dan apa itu jihād. Dan apakah benar bahwa Islam menganjurkan pemeluknya untuk melakukan tindak kekeraan seperti itu?

Pertanyaan-pertanyaan seperti ini membuka ruang dialog yang menuntut Guru Agama Islam untuk menjawabnya. Dan tak kalah pentingnya memberikan penjelasan bahwa Islam melarang tindak kekerasan, dan anarkisme bukanlah bagian dari Islam. Pada sisi lain juga dijelaskan bahwa hal seperti itu tidak mungkin mucul dari kalangan internal Muslim Bali karena konteksnya memang berbeda.

\section{Dinamika Para Guru untuk Tetap Survive di Tengah Kondisi yang Sulit}

\section{a. Problem-problem Internal Guru PAI}

Guru-guru Pendidikan Agama Islam di Bali menghadapai berbagai problem pada yang meliputi berbagai ranah kehidupan. Di sekolah/kelas; Tidak mendapatkan meja kerja sendiri, dianggap tidak ada, tidak pernah mendapat posisi struktural yang berarti, dilibatkan sebagai panitia hanya untuk peranperan yang kecil. In put siswa dengan kemampuan rendah, situasi yang tidak supportive (tidak ada tempat mengajar yang memadai, mengajar di luar jam belajar, PBM PAI bersamaan dengan latihan kesenian/musik yang keras, tidak ada mushalla, saat Jum'atan pelajaran berjalan terus, kasus di sekolah lain. Problem sosial dan lain-lain diantaranya realitas sosial berlawanan dengan nilai-nilai Islam yang dipelajari di sekolah, lingkungan masyarakat adat yang kolot, mengajar di berbagai sekolah untuk mengejar target kerja 24 jam atau memenuhi kebutuhan sekolah-sekolah yang tidak memiliki Guru Agama.

\section{b. Upaya-upaya untuk Tetap Survive}

Agar tetap survive langkah-langkah yang ditempuh oleh para guru antara lain, di sekolah; tetap masuk kantor meskipun harus nebeng di meja kursi orang lain yang kosong, membawakan diri tidak sebagai pengganggu (problem solver), proaktif sehingga keberadaannya dirasakan manfaatnya, menerima tugas utamanya adalah sebagai pendidik bukan birokrat, ada juga yang menjadi Kaur kurikulum, menjadi staf di perpustakaan, mau dilibatkan sebagai panitia meskipun untuk peran-peran yang kecil berarti sudah ada 
pengakuan, biasa menjadi seksi konsumsi pada berbagai kepanitiaan untuk meyakinkn bahwa makanan yang tersaji adalah halal.

Di kelas; bekerja ekstra untuk siswa dengan kemampuan rendah, melaksanakan PAI meskipun dalam siituasi yang sangat terbatas; tidak ada tempat mengajar yang memadai, mengajar di luar jam belajar, PBM PAI tetap dilaksanakan meskipun bersamaan dengan latihan kesenian/musik yang keras, menyediakan sedikit ruang di perpustakaan untuk mushalla.

Problem sosial dan lain-lain diantaranya mengajarkan kepada siswa untuk tetap menjalankan perintah Allah dan meninggalkan hal-hal yang dilarang meskipun realitas sosial berlawanan dengan nilai-nilai Islam yang dipelajari di sekolah, membawakan diri sebaik mungkin di tengah-tengah masyarakat yang sangat majemuk, manajemen waktu sehingga tetap bisa mengajar di berbagai sekolah untuk mengejar target kerja 24 jam atau memenuhi kebutuhan sekolah-sekolah yang ada.

\section{Kurikulum PAI dan Mulok PAI-nya}

Sebagai lembaga pendidikan formal, para guru termasuk Guru Pendidikan Agama Islam dituntut untuk menyampaikan seluruh muatan kurikulum sebagaimana yang telah ditetapkan oleh Departemen Pendidikan Nasional. Hal ini untuk menjamin bahwa siswa lulusan SMP dari Bali memiliki bekal agama yang sama dengan siswa lulusan SMP lain yang ada di Aceh. Di samping itu karena kekhususannya sebagai kaum minoritas, daerah tujuan pariwisata internasional dan ditambah dengan trauma tragedi, ini semua menjadikan guru menerapkan kurikulum lokal yang sesuai dengan tuntutan situasi dan kondisi Bali.

Materi-materi Pendidikan Agama Islam tambahan yang bisa juga disebut kurikulum muatan lokal itu antara lain: (a) menanamkan rasa hormat pada orang lain yang memeluk keyakinan berbeda; (b) mampu memaknai secara positif bahwa perbedaan adalah sumber kekayaan, perbedaan adalah rahmat dan bukan bencana (tasamuh); (c) menumbuhkan sikap saling memahami dan mendukung kelompok atau agama lain agar tetap eksis bukan sebaliknya (sikap proeksisten); (d) menanamkan keyakinan bahwa Islam adalah rahmatan lil 'álamin, Islam kontributif sebagai problem solver bukan problem maker; (e) menghindari konflik dengan warga non-Muslim dalam kehidupan sehari-hari (tasamuh); (f) mampu membedakan antara aqidah 
dan pergaulan serta bisa memposisikan dan menyesuaikan diri tanpa mengorbankan aqidah; (g) tidak mudah terpengaruh issu yang menakutnakuti orang Islam dan tidak terlibat dalam tindak kekerasan.

\section{Rekomendasi}

Belajar dari apa yang bisa diamati selama proses penelitian, juga dari hasil berbagai wawancara dengan para sumber informasi maka ada beberapa rekomendasi yang patut diperhatikan dan ditindaklanjuti oleh berbagai pihak terkait.

\section{a. Kementerian Agama}

Bekerja sama dengan pihak sekolah, pejabat terkait di kementerian agama perlu melakukan pendataan secara cermat tentang siswa Muslim yang ada pada masing-masing sekolah. Hal ini perlu dilakukan untuk memberikan jaminan bahwa setiap siswa yang beragama Islam mendapatkan haknya berupa Pendidikan Agama Islam di sekolah sesuai dengan amanat Undangundang Sistem Pendidikan Nasional. Jika didapati pada satu sekolah hanya ada 3 siswa beragama Islam, memang sangat sulit bagi sekolah terkait dengan pembiayaannya. Dalam konteks inilah kehadiran Kantor Kementerian Agama semakin penting. Selain itu Kementerian Agama perlu melakukan dialog dengan pihak sekolah terkait fasilitas sarana prasarana tempat ibadah.

\section{b. Stakeholders Sekolah}

Pihak sekolah diharapkan support kepada guru Agama Islam dalam hal manajemen jadwal, hal ini perlu karena dengan begitu maka guru Pendidikan Agama Islam akan bisa keberja secara lebih maksimal. Perlu juga dikonsultasikan dengan pihak instansi vertikal terkait tentang kelengkapan sarana prasarana untuk Pendidikan Agama Islam agar hasil Pendidikan Agama Islam lebih maksimal.

\section{c. Para Guru}

Di pundak para guru Pendidikan Agama Islam lah semua harapan akan masa depan kesalehan anak diletakkan. Melihat berbagai tantangan yang ada, guru diharapkan lebih kreatif dalam mengembangkan kurikulum muatan lokal, inovatif dalam pembelajaran, ulet dan tekun dalam kehidupan. Di 
samping itu guru Pendidikan Agama Islam perlu lebih partisipatif dalam program-program sekolah sehingga kehadirannya lebih dirasakan kontributif secara kelembagaan.

\section{d. Peminat Penelitian}

Fokus penelitian ini cukup simpel dan sasaran kajian yang dilakukan juga elementer, oleh karena itu sejumlah sisi dari medan kajian yang sama dapat diteliti secara lebih lanjut, sebagai misal tentang problem-problem pendidikan agama anak pada keluarga dengan orang tua beda agama, konversi agama di kalangan siswa Muslim muallaf, Penidikan Agama khusus Muslim muallaf dan masih banyak tema-tema lain yang terkait.[w] 


\section{BIBLIOGRAFI}

Alwi Shihab, "The Muhammadiyah Movement and It's Controversy with Christian Mission," Ph.D. Dissertation, Temple University, 1995.

Aqib Suminto, Politik Islam Hindia Belanda: Het Kantoor voor Inlandsche zaken, Jakarta: LP3ES, 1985.

Budi Susetyo, D.P., dan St. Hardiyarso, "Stereotip dalam Relasi antar Agama-Studi pada Mahasiswa Islam dan Kristiani di Universitas Katolik Soegijapranata" dalam Proseding Workshop dan Seminar Nasional Hasil-hasil Penelitian, Balitbang Provinsi Jawa Tengah, 16 Desember 2003.

Dadang Kahmad, Sosiologi Agama, Bandung: Rosdakarya, 2000.

Masykuri, dalam artikel online http://islamic-center.or.id/berita-mainmenu26/duniaislam-mainmenu-27/19-duniaislam/496-icis-perkenalkanfiqh-minoritas?tmpl=component\&print=1\& page

Nasikun, Nasionalisme: Refleksi Kritis Kaum Ilmuwan, Yogyakarta: Pustaka Pelajar, 1996.

Noeng Muhadjir, Metode Penelitian Kualitatif, Yogyakarta: Rake Sarasin, 1996. 